\title{
Medication errors in primary care in Riyadh city, Saudi Arabia
}

T. Khoja, ${ }^{1}$ Y. Neyaz, ${ }^{2}$ N.A. Qureshi, ${ }^{3}$ M.A. Magzoub, ${ }^{4}$ A. Haycox ${ }^{5}$ and T. Walley ${ }^{6}$

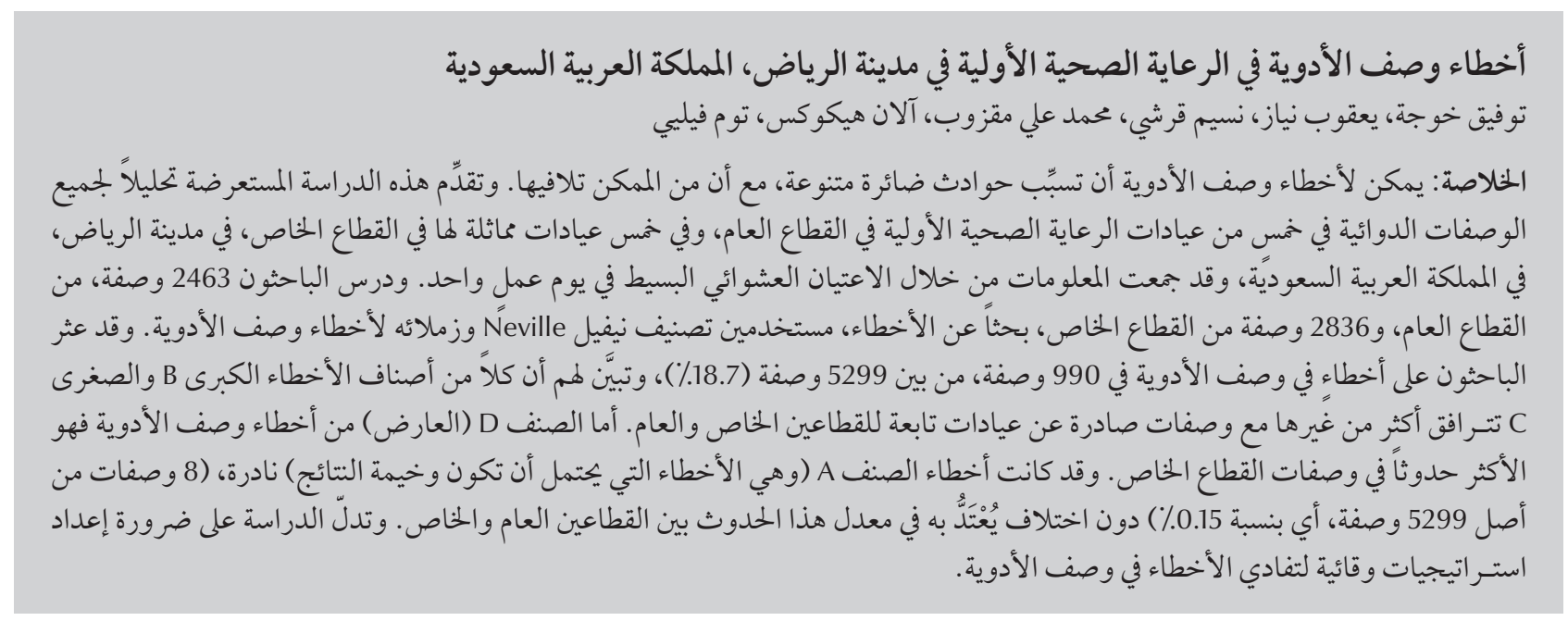

ABSTRACT Medication errors can cause a variety of adverse drug events but are potentially preventable. This cross-sectional study analysed all medication prescriptions from 5 public and 5 private primary health care clinics in Riyadh city, collected by simple random sampling during 1 working day. Prescriptions for 2463 and 2836 drugs from public and private clinics respectively were examined for errors, which were analysed using Neville et al.'s classification of prescription errors. Prescribing errors were found on 990/5299 (18.7\%) prescriptions. Both type B and type C errors (major and minor nuisance) were more often associated with prescriptions from public than private clinics. Type D errors (trivial) were significantly more likely to occur with private health sector prescriptions. Type A errors (potentially serious) were rare (8/5299 drugs; $0.15 \%$ ) and the rate did not differ significantly between the 2 health sectors. The development of preventive strategies for avoiding prescription errors is crucial.

\section{Erreurs de médication en soins de santé primaires à Riyadh (Arabie saoudite)}

RÉSUMÉ Les erreurs de médication peuvent être à l'origine de divers événements iatrogènes médicamenteux. Cependant, elles sont potentiellement évitables. La présente étude transversale a analysé toutes les prescriptions de médicaments issues de dix établissements de soins de santé primaires ( 5 publics et 5 privés) de la ville de Riyadh, collectées par échantillonnage aléatoire simple au cours d'une journée de travail. Les prescriptions de 2463 médicaments pour les établissements publics et de 2836 médicaments pour les établissements privés ont été examinées en vue de détecter d'éventuelles erreurs. Ces dernières ont été analysées au moyen de la classification des erreurs de prescription selon Neville et al. Des erreurs ont été trouvées dans 990 prescriptions de médicaments sur 5299 (18,7\%). Les erreurs de type B et C (conséquences majeures et mineures) étaient plus fréquemment associées aux prescriptions issues des établissements publics qu'à celles des établissements privés. Les erreurs de type D (insignifiantes) étaient nettement plus susceptibles de survenir dans les prescriptions du secteur privé. Les erreurs de type A (potentiellement graves) étaient rares (huit médicaments sur 5299;0,15 \%) et le pourcentage était sensiblement le même entre les deux secteurs de la santé. L'élaboration de stratégies préventives pour éviter les erreurs de prescription est essentielle. 


\section{Introduction}

Prescription errors have been defined as "any preventable event that may cause or lead to inappropriate medication or patient harm when the medication is in the control of the health care professional, patient or consumer" [1]. There are many types of clinical error, caused by a multitude of factors, and these have been reviewed in detail in the literature review accompanying this series of papers [2]. There are also different systems for classifying prescription errors. The Institute of Medicine has categorized 3 types of medical errors that compromise patient outcomes: underuse (failure to prescribe when benefit would be likely), overuse (prescribing when benefit is unlikely) and misuse (an actual error or mistake) [3]. Neville et al. have classified prescription errors into 4 categories on the basis of their potential clinical outcomes [4]: type A (potentially serious to patient); type B (major nuisancepharmacist/doctor contact required); type C (minor nuisance-pharmacist must use professional judgement); and type D (trivial).

At the time of the study, very little information was available about the nature and extent of prescription errors in the Gulf countries. To address this deficiency, samples of prescriptions were analysed to obtain evidence about the nature and extent of errors in primary health care (PHC) in Saudi Arabia. The aim of the study reported here was to identify, analyse and compare the common types of prescription errors encountered in medication prescriptions written in private and public PHC centres in Riyadh city.

\section{Methods}

\section{Setting and sample}

Details of the setting and sample have been described in another paper [5]. Patient clinical management records were collected by simple random sampling during 1 working day from 5 public and 5 PHC clinics in Riyadh city. The records were examined and all prescriptions for medications from all consultations on the day of the study were analysed: 1182 from public and 1200 from private PHC centres. As most prescriptions were for more than 1 drug a total of 2463 prescribed drugs from public clinics and 2836 from private clinics were analysed.

\section{Data collection}

Data were collected by the investigator (Y.N.) and entered by 2 trained graduate research assistants. Prescriptions containing errors were allocated an error classification following a discussion between the investigator (Y.N.) and the pharmacists involved. Neville et al.'s system for classifying prescription errors was used to classify errors as type A, B, C or D [4]. As a quality assurance measure, all classifications were doublechecked by another pharmacist. In no case was there disagreement with regard to the category of error between the investigator and the pharmacists.

\section{Data analysis}

The data were entered in the computer using SPSS software program, version 10. Analysis was conducted following data cleaning and quality testing. Frequencies were computed for all variables under investigation and the chi-squared test was used to analyse categorical variables.

\section{Results}

A total of 2463 prescribed drugs were analysed from public clinics and 2836 from private clinics. Overall, prescribing errors were found on 990 out of 5299 prescriptions (18.7\%).

The analysis of error types (Table 1) revealed that both type $\mathrm{B}$ and type $\mathrm{C}$ errors were more common in public than private $\mathrm{PHC}$ centres. Type $\mathrm{B}$ errors were detected in $8.0 \%$ versus $6.0 \%$ of drugs prescribed by public and private clinics respectively and type $\mathrm{C}$ errors were found in $2.2 \%$ versus $1.1 \%$ drugs prescribed by public and private clinics respectively $(P<0.05)$. In contrast, the more trivial type of error (type D) were more frequently found on private than public clinic prescriptions (11.2\% versus $8.5 \%)(P<0.05)$. For the most serious type of error (type A), no significant differences were observed between the 2 types of PHC centres; however, only 8 such errors were identified in total, an overall rate of $0.15 \%$ (8/5299) of all drugs prescribed;

Potentially life-threatening type A errors in both sectors were mainly

\begin{tabular}{|c|c|c|c|c|c|c|}
\hline \multirow[t]{2}{*}{ Type of prescription error ${ }^{a}$} & \multicolumn{2}{|c|}{$\begin{array}{l}\text { Public PHC centres } \\
\qquad(n=2463)\end{array}$} & \multicolumn{2}{|c|}{$\begin{array}{l}\text { Private PHC centres } \\
\qquad(n=2836)\end{array}$} & \multirow[t]{2}{*}{$\chi^{2}$-value ${ }^{b}$} & \multirow[t]{2}{*}{$P$-value } \\
\hline & No. & $\%$ & No. & $\%$ & & \\
\hline Type A (serious) & 3 & 0.1 & 5 & 0.2 & 0.3 & NS \\
\hline Type B (major nuisance) & 198 & 8.0 & 171 & 6.0 & 6.2 & 0.004 \\
\hline Type C (minor nuisance) & 54 & 2.2 & 32 & 1.1 & 9.3 & 0.002 \\
\hline Type D (trivial) & 209 & 8.5 & 318 & 11.2 & 10.9 & 0.0001 \\
\hline
\end{tabular}

$n=$ number of prescribed drugs analysed; $N S=$ not significant.

${ }^{a}$ Neville et al.'s classification [4]. ${ }^{b}$ Degrees of freedom $=1$. 
related to overdosage. These errors were most commonly associated with drugs for diabetes or hypertension, frequently by a factor of 10; for example, $50 \mathrm{mg}$ instead of $5 \mathrm{mg}$ Daonil (glibenclamide) and $500 \mathrm{mg}$ instead of $50 \mathrm{mg}$ propranolol. No evidence was available to indicate whether such serious errors had been corrected prior to dispensing the medication to patients.

Type B errors are those in which the nature of the prescription required is completely unclear. In such errors, the pharmacist would have to contact the physician to clarify the nature of the prescription. An average of $7 \%$ of all drugs prescribed were classified as type B; for example, writing antihistamine syrup without mentioning the dose to be given per day. Many such errors were also related to bad handwriting. In one notable example it was difficult for the dispensing pharmacist to read amoxicillin antibiotic written for fever for a young adult. These types of errors were time-consuming because frequently the prescribing physicians were difficult to contact by the pharmacist in order to clarify the prescription.

Type $\mathrm{C}$ errors denote a minor nuisance, requiring the pharmacist to make a professional decision before dispensing the prescribed medication, which inconveniences both the pharmacist and the patient. An example of this was the issuing of prescriptions for an inappropriate duration, which appeared to exceed therapeutic requirements.

Type D errors denote a trivial issue, for example when the prescription does not conform to the guidelines in the Ministry of Health formulary, although the intentions of the prescriber are not in doubt. Examples included the prescribing of liquid formations instead of gel with antacid preparations or obvious spelling errors. Spelling errors were the most commonly observed type D prescription errors; for example, writing claoxacilin for cloxacillin, Actifid for Actifed and Dainil for Daonil.

\section{Discussion}

Another study using the same patient records has explored the extent to which prescriptions in PHC centres in Riyadh city were complete and readable [5]. Incomplete information included demographic details, e.g. patient's address, age and sex or, more importantly, clinical details, e.g. drug strength/dose/ frequency and duration of treatment. The study reported in this paper explored the extent of errors of commission, i.e. writing incorrect information about the medication or the patient. The findings emphasize that both public and private sector physicians were failing to provide the necessary information to allow safe dispensing and administration of drugs. Error rates were significantly different between the 2 sectors, with the rate of type $B$ and $C$ errors being significantly higher in public $\mathrm{PHC}$ clinics as compared to private clinics. There was no statistical difference in the rate of serious type A reactions between the public and private sectors, probably due to the small number of such events (8 in total).

These results reflect those reported in other studies [6-11]. In Bahrain, Al Khaja et al. explored prescription errors and found similar patterns of prescribing to those identified in our study [10]. According to their study, 5959 out of 77511 prescriptions dispensed (7.7\%) were found to contain errors compared with 990 out of 5299 (18.7\%) in the current study. The authors made a series of recommendations including training initiatives to improve physicians' prescribing skills, adherence to the essential drugs list and use of the national formulary to reduce medication errors in the PHC setting [10].

In a study of hospitalized patients, Blix et al. reported that $81 \%$ of patients had problems with their drug prescriptions, most commonly for drugs such as warfarin, digoxin and prednisolone [12]. In a study of 4 UK primary care pharmacies, Chua et al. reported that "near misses" occurred 6 times more often than dispensing errors, indicating the importance of final checking in pharmacies. The most common types of dispensing errors or near misses appeared to be incorrect strength of medication, incorrect drugs, incorrect quantities, incorrect dosage and incorrect labels. This group of investigators further emphasized the importance of a self-reporting scheme [13].

Prescription errors are potentially preventable, and concerted efforts by health providers, health consumers and well organized health delivery systems [14] would reduce the incidence of such errors. Key elements for achieving this objective are enhanced education about prescribing [15], access to drug formularies, computer-aided prescribing and high-quality drug information services [16]. Better education for patients and improved organization of prescribing are also crucial [17]. Accurate drug error reporting systems will guide the development of preventive strategies for reducing the magnitude and implications of prescription errors $[18,19]$. A recent study of medication errors emphasized that even hospitals using highly developed computerized prescribing systems may have high rates of adverse drug events [20] and related problems [21]. Many prescription errors are potentially preventable if effective preventive strategies can be applied in a timely fashion [22].

The results obtained in this study shouldbeperceived as being preliminary and indicative rather than definitive. Lack of any independent verification concerning the accuracy of diagnosis makes it impossible to determine what proportion of patients was subject to incorrect diagnosis and hence incorrect prescriptions. One potential enhancement of this research would be to cross-check the diagnosis to assess the accuracy with which public and private physicians can determine this crucial element. Furthermore, this study has applied a particular classification system 
for prescription errors. It would be instructive to assess the extent to which the use of other classification systems would affect the classification of the prescription errors identified.

To sum up, this study has revealed multiple prescription error types across both public and private settings, compatible with findings reported in the national and international literature. Most of these errors were of limited clinical significance, and the incidence of serious errors was low at $0.15 \%$. The major area for prescription errors, incorrect diagnosis, was not studied here because of the nature of the data available. The development of preventive strategies for avoiding prescription errors is crucial in Saudi Arabia, as most errors, and their potentially serious adverse consequences, are potentially preventable.

\section{References}

1. United States pharmacopoeia. The standard. Rockville, Maryland, U.S. Pharmacopoeia, 1995.

2. Qureshi NA. Physicians' medication prescribing in primary care in Riyadh city, Saudi Arabia. Literature review, part 3: prescribing errors. Eastern Mediterranean Health Journal, 2011, 17(2):134-139.

3. Chassin MR, Galvin RW; Institute of Medicine National Roundtable on Health Care Quality. The urgent need to improve health care quality. Journal of the American Medical Association, 1998, 280:1000-1005.

4. Neville RG et al. A classification of prescription errors. Journal of the Royal College of General Practitioners, 1989, 39:110-112.

5. Neyaz $\mathrm{Y}$ et al. Medication prescribing pattern in primary care in Riyadh city, Saudi Arabia. Eastern Mediterranean Health Journal, 2011, 17(2):149-155.

6. Al-Nasser AN. Prescribing patterns in primary healthcare in Saudi Arabia. Annals of Pharmacotherapy, 1991, 25:90-93.

7. Al-Faris EA, Al Taweel A. Audit of prescribing patterns in Saudi primary health care: What lessons can be learned? Annals of Saudi Medicine, 1999, 19:317-321.

8. Khoja TA et al. Quality of prescribing at primary care centres in Saudi Arabia. Journal of Pharmacy Technology, 1996, 12:284-288.

9. Adubofour $\mathrm{KO}$ et al. Strategies to reduce medication errors in ambulatory practice. Journal of the National Medical Association, 2004, 96:1558-1564.

10. Al Khaja KA, Al-Ansari TM, Sequeira RP. An evaluation of prescribing errors in primary care in Bahrain. International Journal of Clinical Pharmacology and Therapeutics, 2005, 43:294-301.

11. Sandars J, Esmail A. The frequency and nature of medical error in primary care: understanding the diversity across studies. Family Practice, 2003, 20:231-236.
12. Blix HS et al. The majority of hospitalised patients have drugrelated problems: results from a prospective study in general hospitals. European Journal of Clinical Pharmacology, 2004, 60:651-658.

13. Chua SS et al. A feasibility study for recording of dispensing errors and near misses' in four UK primary care pharmacies. Drug Safety, 2003, 26:803-813.

14. Avery AJ et al. Safer medicines management in primary care. British Journal of General Practice, 2002, 52(Suppl.):S17-S22.

15. Bateman DN et al. Setting standards of prescribing performance in primary care: use of a consensus group of general practitioners and application of standards to practices in the north of England. British Journal of General Practice, 1996, 46:20-25.

16. Upperman JS et al. The impact of hospitalwide computerized physician order entry on medical errors in a pediatric hospital. Journal of Pediatric Surgery, 2005, 40:57-59.

17. Metlay JP et al. Medication safety in older adults: home-based practice patterns. Journal of the American Geriatrics Society, 2005, 53:976-982.

18. Westfall JM et al. Applied strategies for improving patient safety: a comprehensive process to improve care in rural and frontier communities. Journal of Rural Health, 2004, 20:355-362.

19. Capuzzo $M$ et al. Reporting of unintended events in an intensive care unit: comparison between staff and observer. BMC Emergency Medicine, 2005, 5:3.

20. Nebeker JR, Barach P, Samore MH. Clarifying adverse drug events: a clinician's guide to terminology, documentation, and reporting. Annals of Internal Medicine, 2004, 140:795-801.

21. Wilson T, Sheikh A. Enhancing public safety in primary care. British Medical Journal, 2002, 324:584-587.

22. Dowell D et al.; MEMO Investigators. Urban outpatient views on quality and safety in primary care. Healthcare Quarterly (Toronto, Ont.), 2005, 8:2-8. 